\title{
INVESTIGATION OF GENETIC VARIABILITY PARAMETERS FOR Septoria tritici BLOTCH RESISTANCE AND QUANTITATIVE TRAITS IN BREAD WHEAT GENOTYPES
}

\author{
Geleta Gerema $^{1}$, Dagnachew Lule ${ }^{2}$ and Fikre Lemessa ${ }^{3}$ and Tilahun Mekonnen ${ }^{4}$ \\ ${ }^{1}$ Bako Agriculture Research Center, Oromia, Ethiopia \\ ${ }^{2}$ Oromia Agriculture Research Institute, Finfinne, Ethiopia \\ ${ }^{3}$ Jimma University, Department of Horticulture and Plant Science, Jimma, Ethiopia \\ ${ }^{4}$ Addiss Ababa University Institute of Biotechnology, Ethiopia
}

\begin{abstract}
Septoria tritici Blotch (STB) is one of the most devastating diseases of wheat in Ethiopia and worldwide. The present study was conducted to assess the genetic variability of yield and yield parameters among different bread wheat genotypes grown under the stress of Septoria tritici Blotch. A total of 180 bread wheat lines, advanced genotypes and released varieties were included in the investigation. Genetic variance, heritability, correlation and ANOVA were estimated for S.tritici, and yield and yield parameters. The genetic variance was relatively high for grain yield, percentage of disease severity (\% severity) and Septoria progress coefficient (SPC). Heritability and genetic advance were relatively higher for grain yield, and moderate heritability and high genetic advance were computed for disease parameters such as coverage of pycnidia, Septoria progress coefficient and \% severity. A negative correlation was found between plant height and pycnidia coverage on the four uppermost leaves (PCD), SPC and severity. Days to maturity and heading inversely correlated with disease resistance parameters. This indicated that the genotypes having short plant height and short maturity period could be resistant to Septoria tritici Blotch. The results help researchers to utilize the promising genotypes of this study in future breeding programmers for narrowing the yield gaps between the potential and actual in the areas where the Septoria tritici Blotch infection is a problem.
\end{abstract}

\section{INTRODUCTION}

Wheat is one of the food security crops at the global level with an annual volume of production and area coverage of 750 million tons and 220 million ha, respectively in 2017 (FAO 2017). Sub-Sahara Africa (SSA) produced wheat with an annual production of 7.5 million tons on a total area of 2.9 million hectares accounting for $40 \%$ and $1.4 \%$ of the total in Africa and at global levels, respectively (FAO 2017). Ethiopia is the second-largest wheat producer in Sub-Saharan Africa (SSA) next to South Africa (Tadesse et al. 2018). There is a broad range of factors affecting

*Corresponding author: geletarabi@gmail.com wheat productivity in Ethiopia. Actual productivity and yield stability of wheat in Ethiopia are influenced by abiotic factors such as climate change, increased intensity drought and heat, and biotic factors including weeds and several pathogens (Rezenne 1993; Hailu and Mengistu 1991; Hailu and Woldeab 2015; Tadesse et al. 2018). Septoria tritici blotch (STB), caused by Zymoseptoria tritici, is among the most devastating foliar diseases of wheat (Kidane et al. 2017). S. tritici causes premature death of wheat leaves, hampers photosynthesis, and ultimately reduces grain production (Kidane et al. 2017). Both farming practices and weather patterns influence $S$. 
tritici disease severity, as Zymoseptoria tritici requires a moist leaf surface for a successful infection, and spreads throughout the crop canopy via rain splash (Gladders et al. 2001; Pietravalle et al. 2003). This disease impacts wheat production in Europe, Mediterranean area, Africa including Ethiopia, Americas, and Australia (Kosina et al. 2007; Ponomarenko et al. 2011; Dean et al. 2012; Fones and Gurr 2015 ) where, under favorable environmental conditions, can cause significant yield losses (Eyal 1999; Duveiller et al. 2007). The crop loss due to $S$. tritici may go up to $82 \%$ (Mengistu et al. 1991, Ayele et al. 2008) and $40 \%$ loss reported recently in Ethiopia (Abera et al. 2015). Severe epidemics of STB can reduce wheat yields by 35 to $50 \%$ (Ponomarenko et al. 2011). Fungicide application is one of the options for the management of $S$. tritici disease. The application of fungicides has some side effects such as it could lead to the rapid emergence of fungicide resistance strains and high costs in subsequent control of the disease (Cools and Fraaije 2013; Leroux et al. 2007; Torriani et al. 2009). Therefore, the development of resistant wheat cultivars is the most effective, economic and environmentally-safe strategy to control this disease (Eyal and Ziv 1974; Eyal 1999). Host plant resistance is the method of choice for the control of $S$. tritici (Cowger et al. 2000). Therefore, genetic diversity is a vital source for screening various disease resistance and high yielding genes. The dissimilar genetic sources provide desirable allelic variation in parental lines to produce new genetic combinations (Tar'an et al. 2005). Therefore, in this investigation, different genotypes were evaluated in an attempt to generate information and identify disease resistance that aid in the selection of better genotypes for further breeding activities. Therefore, the present study aims to: (1) study the level of genetic variability in bread wheat genotypes under the stress of $S$. tritici (2) assess the degree of correlation among yield and disease parameters. (3) identify $S$. tritici resistance bread wheat genotypes for utilization in the future breeding programs.

\section{MATERIAL AND METHODS \\ Experimental materials and field management}

One hundred and eighty (180) bread wheat genotypes consisted of improved varieties (11), candidate varieties (8) and lines (161) were collected from different Agricultural Research Centers in Ethiopia, the International Maize and Wheat Improvement Center (CIMMYT) and International Center for Agricultural Research in the Dry Areas (ICARDA). The details of the genotypes are given in Tables 1 and 2. The genotypes were grown in alphalattice design with three replications at Gedo station of Bako Agricultural Research Center during the main season of 2017/18. Each plot consisted of four rows of $2.5 \mathrm{~m}$ length with $20 \mathrm{~cm}$ and $50 \mathrm{~cm}$ spacing between rows and plots, respectively. The seed rate of $150 \mathrm{~kg}$ ha -1 and fertilizer rate of $100 \mathrm{~kg}$ ha- 1 of NPS and $100 \mathrm{~kg}$ ha-1 urea were used. NPS is a compound fertilizer containing nitrogen, phosphorous and sulfur with the ratio of $19 \%$ $\mathrm{N}, 38 \%$ P2O5 and 7\% S. All other crop management and protection practices were undertaken following previous research recommendations for bread wheat production (BARC 2019).

To enhance $S$. tritici infection, in addition to natural infection, plants were inoculated by spreading chopped infected wheat straw between the rows. It is the cheapest and the easiest method to induce disease infection, as infected leaves are easily available in infected wheat farms and it couldn't need special techniques for application. Besides, a mixture of several susceptible varieties (Kubsa and Digalu) was planted around the experimental plots as infector/spreader rows to increase disease infection intensity.

\section{Collection of data on Disease severity}

The severity of $S$. tritici was examined using the double-digit scale (00-99) developed as a 
Table 1. List of bread wheat lines used in the experiment

\begin{tabular}{|c|c|c|c|c|c|}
\hline & Acc & & & Acc & \\
\hline No & no & Pedigree & No & no & Pedigree \\
\hline 1 & 1092 & MXI12-13\M47IBWSN/194 & 82 & 85 & $\mathrm{AON}$ \\
\hline 2 & 6223 & MXI12-13 \M24ISEPTON\56 & 83 & 2122 & MXI12-13\M25HRWSN $\backslash 1148$ \\
\hline 3 & 6201 & MXI12-13\M24ISEPTON\25 & 84 & 86 & $\mathrm{AON}$ \\
\hline 4 & 61 & $\mathrm{AON}$ & 85 & 6220 & MXI12-13\M24ISEPTON $\backslash 36$ \\
\hline 5 & 2042 & MXI12-13 \M25HRWSN \1053 & 86 & 2014 & MXI12-13\M25HRWSN $\backslash 1012$ \\
\hline 6 & 6208 & MXI12-13\M24ISEPTON\96 & 87 & 94 & $\mathrm{AON}$ \\
\hline 7 & 1108 & MXI12-13\M47IBWSN/247 & 88 & 1279 & MXI12-13〈M47IBWSN $\backslash 779$ \\
\hline 8 & 20 & Adap & 89 & 6207 & MXI12-13 \M24ISEPTON $\backslash 102$ \\
\hline 9 & 6239 & MXI12-13\M24ISEPTON\26 & 90 & 6218 & MXI12-13 \M24ISEPTON $\backslash 13$ \\
\hline 10 & 1102 & MXI12-13\M47IBWSN/222 & 91 & 6203 & MXI12-13 \M24ISEPTON $\backslash 63$ \\
\hline 11 & 6229 & MXI12-13\M24ISEPTON\95 & 92 & 1299 & MXI12-13\M47IBWSN $\backslash 847$ \\
\hline 12 & 2 & Adap & 93 & 6241 & MXI12-13\M24ISEPTON \66 \\
\hline 13 & 2132 & MXI12-13\M25HRWSN \1166 & 94 & 63 & $\mathrm{AON}$ \\
\hline 14 & 6221 & $\underline{\| 0}$ & 95 & 1179 & MXI12-13\M47IBWSN\496 \\
\hline 15 & 2034 & $\overline{M X I 12-13 \backslash M 25 H R W S N \backslash 1041 ~}$ & 96 & 9217 & MXI12-13\M24ISEPTON $\backslash 97$ \\
\hline 16 & 2083 & MXI12-13 \M25HRWSN $\backslash 1100$ & 97 & 2010 & MXI12-13\M25HRWSN $\backslash 1007$ \\
\hline 17 & 1096 & MXI12-13\M47IBWSN/208 & 98 & 6219 & MXI12-13 \M24ISEPTON $\backslash 44$ \\
\hline 18 & 80 & $\mathrm{AON}$ & 99 & 40 & $\mathrm{AON}$ \\
\hline 19 & 1242 & MXI12-13\M47IBWSN/655 & 100 & 1295 & MXI12-13\M47IBWSN $\backslash 830$ \\
\hline 20 & 1161 & MXI12-13\M47IBWSN/415 & 101 & 2105 & MXI12-13\M25HRWSN $\backslash 1124$ \\
\hline 21 & 5 & Adap & 102 & 1034 & MXI12-13\M47IBWSN\74 \\
\hline 22 & 1141 & MXI12-13\M47IBWSN/335 & 103 & 1097 & MXI12-13\M47IBWSN $\backslash 217$ \\
\hline 23 & 73 & $\mathrm{AON}$ & 104 & 6235 & MXI12-13 \M24ISEPTON $\backslash 62$ \\
\hline 24 & 1087 & MXI12-13\M47IBWSN/185 & 105 & 6242 & MXI12-13 \M24ISEPTON $\backslash 73$ \\
\hline 25 & 1089 & MXI12-13\M47IBWSN/188 & 106 & 51 & $\mathrm{AON}$ \\
\hline 26 & 2106 & MXI12-13\M25HRWSN \1127 & 107 & 6216 & MXI12-13\M24ISEPTON $\backslash 42$ \\
\hline 27 & 67 & $\mathrm{AON}$ & 108 & 2135 & MXI12-13\M25HRWSN $\backslash 1174$ \\
\hline 28 & 6205 & MXI12-13\M24ISEPTON\89 & 109 & 6211 & MXI12-13 \M24ISEPTON $\backslash 74$ \\
\hline 29 & 1265 & MXI12-13 \M47IBWSN $\backslash 722$ & 110 & 2131 & MXI12-13\M25HRWSN $\backslash 1162$ \\
\hline 30 & 2114 & MXI12-13 \M25HRWSN $\backslash 1138$ & 111 & 71 & $\mathrm{AON}$ \\
\hline 31 & 6230 & MXI12-13\M24ISEPTON\32 & 112 & 87 & $\mathrm{AON}$ \\
\hline 32 & 1178 & MXI12-13\M47IBWSN/492 & 113 & 6228 & MXI12-13\M24ISEPTON $\backslash 20$ \\
\hline 33 & 2082 & MXI12-13\M25HRWSN \1099 & 114 & 2104 & MXI12-13\M25HRWSN $\backslash 1123$ \\
\hline 34 & 6240 & MXI12-13\M24ISEPTON\85 & 115 & 6214 & MXI12-13 \M24ISEPTON $\backslash 51$ \\
\hline 35 & 2123 & MXI12-13 \M25HRWSN $\backslash 1150$ & 116 & 52 & $\mathrm{AON}$ \\
\hline 36 & 58 & $\mathrm{AON}$ & 117 & 2136 & MXI12-13 \M25HRWSN $\backslash 1175$ \\
\hline 37 & 1103 & MXI12-13\M47IBWSN $\backslash 224$ & 118 & 1294 & MXI12-13 \M47IBWSN $\backslash 823$ \\
\hline 38 & 1293 & MXI12-13\M47IBWSN $\backslash 811$ & 119 & 6210 & MXI12-13\M24ISEPTON $\backslash 71$ \\
\hline 39 & 2115 & MXI12-13 \M25HRWSN \1141 & 120 & 2133 & MXI12-13\M25HRWSN $\backslash 1169$ \\
\hline 40 & 2108 & MXI12-13\M25HRWSN \1129 & 121 & 2113 & MXI12-13\M25HRWSN $\backslash 1137$ \\
\hline 41 & 1015 & MXI12-13\M47IBWSN/25 & 122 & 1033 & MXI12-13\M47IBWSN $\backslash 73$ \\
\hline 42 & 1185 & MXI12-13\M47IBWSN\517 & 123 & 70 & $\mathrm{AON}$ \\
\hline
\end{tabular}


Table 1 continued

\begin{tabular}{|c|c|c|c|c|c|}
\hline \multicolumn{3}{|c|}{ Acc } & \multicolumn{3}{|c|}{ Acc } \\
\hline No & no & Pedigree & No & no & Pedigree \\
\hline 43 & 2058 & MXI12-13\M25HRWSN $\backslash 1074$ & 124 & 1029 & MXI12-13 \M47IBWSN $\backslash 64$ \\
\hline 44 & 6237 & MXI12-13\M24ISEPTON\2 & 125 & 2121 & MXI12-13 \M25HRWSN $\backslash 1147$ \\
\hline 45 & 4 & $\mathrm{AON}$ & 126 & 2011 & MXI12-13 \M25HRWSN $\backslash 1008$ \\
\hline 46 & 1099 & MXI12-13\M47IBWSN/220 & 127 & 1041 & MXI12-13 \M47IBWSN $\backslash 95$ \\
\hline 47 & 6215 & MXI12-13\M24ISEPTON\4 & 128 & 60 & $\mathrm{AON}$ \\
\hline 48 & 1101 & MXI12-13\M47IBWSN/221 & 129 & 6206 & MXI12-13 \M24ISEPTON $\backslash 55$ \\
\hline 49 & 3 & $\mathrm{AON}$ & 130 & 1035 & MXI12-13\M47IBWSN\78 \\
\hline 50 & 6209 & MXI12-13 \M24ISEPTON\31 & 131 & 1236 & MXI12-13\M47IBWSN $\backslash 644$ \\
\hline 51 & 7 & Adap & 132 & 6202 & MXI12-13 \M24ISEPTON $\backslash 12$ \\
\hline 52 & 82 & $\mathrm{AON}$ & 133 & 6246 & MXI12-13 \M24ISEPTON $\backslash 16$ \\
\hline 53 & 1143 & MXI12-13 $\backslash$ M47IBWSN $\backslash 345$ & 134 & 2126 & MXI12-13 \M25HRWSN $\backslash 1154$ \\
\hline 54 & 1030 & MXI12-13\M47IBWSN $\backslash 69$ & 135 & 2125 & MXI12-13 \M25HRWSN $\backslash 1152$ \\
\hline 55 & 95 & $\mathrm{AON}$ & 136 & 39 & K6295-4A \\
\hline 56 & 62 & $\mathrm{AON}$ & 137 & 2117 & MXI12-13\M25HRWSN $\backslash 1144$ \\
\hline 57 & 6226 & MXI12-13 \M24ISEPTON $\backslash 34$ & 138 & 77 & $\mathrm{AON}$ \\
\hline 58 & 6245 & MXI12-13 \M24ISEPTON $\backslash 88$ & 139 & 84 & $\mathrm{AON}$ \\
\hline 59 & 66 & $\mathrm{AON}$ & 140 & 6238 & MXI12-13 \M24ISEPTON $\backslash 58$ \\
\hline 60 & 1093 & MXI12-13\M47IBWSN\196 & 141 & 2023 & MXI12-13 \M25HRWSN $\backslash 1023$ \\
\hline 61 & 6213 & MXI12-13 \M24ISEPTON $\backslash 18$ & 142 & 72 & $\mathrm{AON}$ \\
\hline 62 & 6224 & MXI12-13 \M24ISEPTON\99 & 143 & 2059 & MXI12-13\M25HRWSN $\backslash 1075$ \\
\hline 63 & 2107 & MXI12-13\M25HRWSN $\backslash 1128$ & 144 & 55 & $\mathrm{AON}$ \\
\hline 64 & 6227 & MXI12-13 \M24ISEPTON $\backslash 65$ & 145 & 12 & $\mathrm{AON}$ \\
\hline 65 & 69 & $\mathrm{AON}$ & 146 & 31 & $\mathrm{AON}$ \\
\hline 66 & 2033 & MXI12-13\M25HRWSN $\backslash 1040$ & 147 & 1042 & MXI12-13\M47IBWSN $\backslash 96$ \\
\hline 67 & 6234 & MXI12-13 \M24ISEPTON $\backslash 92$ & 148 & 1172 & MXI12-13 \M47IBWSN $\backslash 470$ \\
\hline 68 & 1162 & MXI12-13\M47IBWSN $\backslash 418$ & 149 & 6222 & $\underline{\| 0}$ \\
\hline 69 & 2012 & MXI12-13\M25HRWSN \1009 & 150 & 4 & Adap \\
\hline 70 & 1241 & MXI12-13\M47IBWSN $\backslash 653$ & 151 & 1037 & MXI12-13 \M47IBWSN $\backslash 82$ \\
\hline 71 & 6243 & MXI12-13 \M24ISEPTON\69 & 152 & 2103 & MXI12-13 \M25HRWSN $\backslash 1122$ \\
\hline 72 & 16 & $\mathrm{AON}$ & 153 & 79 & $\mathrm{AON}$ \\
\hline 73 & 2134 & MXI12-13\M25HRWSN $\backslash 1170$ & 154 & 6232 & MXI12-13 \M24ISEPTON $\backslash 33$ \\
\hline 74 & 6225 & MXI12-13\M24ISEPTON $\backslash 83$ & 155 & 44 & K6290-Bulk \\
\hline 75 & 2013 & MXI12-13\M25HRWSN \1011 & 156 & 89 & $\mathrm{AON}$ \\
\hline 76 & 6204 & MXI12-13 \M24ISEPTON $\backslash 86$ & 157 & 83 & $\mathrm{AON}$ \\
\hline 77 & 6244 & MXI12-13 \M24ISEPTON $\backslash 70$ & 158 & 1104 & MXI12-13\M47IBWSN 2225 \\
\hline 78 & 6212 & MXI12-13\M24ISEPTON $\backslash 101$ & 159 & 6236 & MXI12-13 \M24ISEPTON $\backslash 50$ \\
\hline 79 & 74 & $\mathrm{AON}$ & 160 & 1032 & MXI12-13 \M47IBWSN $\backslash 72$ \\
\hline 80 & 6231 & MXI12-13 \M24ISEPTON $\backslash 23$ & 161 & 6233 & MXI12-13\M24ISEPTON\78 \\
\hline 81 & 1036 & MXI12-13\M47IBWSN $\backslash 81$ & & & \\
\hline
\end{tabular}

Source: CIMMYT - The International Maize and Wheat Improvement Center 
Table 2: Description of bread wheat genotypes (released and candidate varieties) used in the experiment

\begin{tabular}{lllll}
\hline Sr No & Genotypes & Breeding Center & Year of release & $\begin{array}{c}\text { Adaptation area } \\
\text { (altitude, } \mathrm{m} \text { asl) }\end{array}$ \\
\hline 1 & Danda'a & EAIR/KARC & 2010 & $2000-2600$ \\
2 & ET-13A2 & EAIR/KARC & 1981 & $2200-2900$ \\
3 & Alidoro & EAIR/HARC & 2007 & $2200-2900$ \\
4 & Huluka & EAIR/KARC & 2011 & $2200-2600$ \\
5 & Hoggana & EAIR/KARC & 2011 & $2200-2800$ \\
6 & Sofumar & OARI/SARC & $1999 / 00$ & $2300-2800$ \\
7 & King bird & EAIR/KARC & 2015 & $-1900-2800$ \\
8 & Madda walabu & OARI/SARC & $1999 / 00$ & - \\
9 & Merero & OARI/SARC & - & $750-2500$ \\
10 & Bika & EAIR/KARC & 2014 & \\
11 & Pavon-76 & EAIR/KARC & 1982 & \\
12 & Acc//23 & EAIR/KARC & NR & \\
13 & Acc//24 & EAIR/KARC & NR & \\
14 & Acc//15 & EAIR/KARC & NR & \\
15 & Acc//25 & EAIR/KARC & NR & \\
16 & Acc//27 & EAIR/KARC & NR & \\
17 & Acc//255 & OARI/SARC & NR & \\
18 & Acc//9 & OARI/SARC & NR & \\
19 & Acc//12 & EAIR/KARC & NR & \\
\hline
\end{tabular}

Key: Acc $=$ Accession, HARC $=$ Holeta Agricultural Research Center, KARC $=$ Kulumsa Agricultural Research Center, $\mathrm{NR}=$ Not released, $\mathrm{SARC}=$ Sinana Agricultural Research Center.

modification of Saari and Prescott's severity scale to assess wheat foliar diseases (Saari and Prescott 1975; Eyal et al. 1987). The first digit (D1) indicates vertical disease progress on the plant and the second digit (D2) refers to severity measured as diseased leaf area. Ten plants were randomly selected from each plot and tagged at the vegetative stage or before heading. Disease rating was done on the tagged plants continued until crops physiological maturity every 7 days intervals and thus assessed 7 times for all leave and 4 times for flag leaf.

\section{Disease progress analysis and modeling}

The area under disease progress curve (AUDPC) and growth curve models were developed for the disease progress data. An
AUDPC value was calculated for each plot using the formula indicated below, which was stated by Campbell and Madden (1990).

$$
\text { AUDPC }=\sum_{i=1}^{n-1} 0.5\left(x_{i+1}+x_{i}\right)\left(t_{i+1}-t_{i}\right)
$$

Where $n$ is the total number of assessment times, $t i$ is the time of the ith assessment in days from the first assessment date, xi is the percentage of disease severity at $i^{\text {th }}$ assessment.

\section{Percentage of disease severity}

Percent disease severity was estimated based on the formula adopted from Saari and Prescott (1975) as indicated below, 


$$
\% \text { Severity }=(\mathrm{Y} 1 / 9) \times(\mathrm{Y} 2 / 9) \times 100
$$

Where D1 and D2 represent the score recorded (00-99 scale) and $Y 1$ and $Y 2$ represent the maximum score on the scale ( 9 and 9) (Sharma and Duveiller 2007).

\section{Septoria progress of coefficient}

To overcome some of the difficulties associated with plant growth habit (maturity and height) and the expression of symptoms, Eyal and Ziv (1974) have used the Septoria Progress Coefficient (SPC) together with an evaluation of disease severity. Plant and disease height $(\mathrm{cm})$ were used to determine the Septoria Progress Coefficient. Disease height is the maximum height $(\mathrm{cm})$ from the ground where pycnidia of the pathogen are found on the plant. The SPC was computed as follows,

SPC $=$ Disease height $(\mathrm{cm}) /$ Plant height $(\mathrm{cm})$ (Eyal and Ziv 1974)

\section{Estimation of variance components}

Environmental variance or error variance $(\delta 2 \mathrm{e})$, genotypic variance $(\delta 2 \mathrm{~g})$ and phenotypic variance $(\delta 2 \mathrm{p})$ components and their coefficients of variation were estimated as suggested by Singh, (2001). The equations are as follows,

$$
\text { Genotipic Variance }\left(\sigma^{2} g\right)=\frac{\text { GMS }- \text { MSE }}{r}
$$

Where; $M S G=$ mean square of genotypes, $M S E=$ mean square of error, $r=$ Number of replication.

Phenotypic variance $\left(\delta^{2} \mathrm{p}\right)=$

$$
\sigma^{2} p=\sigma^{2} g+\sigma^{2} e \sigma^{2} p=\sigma^{2} g+\sigma^{2} e
$$

Where: $\delta 2 p=$ phenotypic variance, $\delta 2 g=$ genotypic variance, $\delta 2 e=$ Environmental variance or error variance.
The phenotypic (PCV) and genotypic (GCV) coefficients of variations were estimated as the percentage of the corresponding phenotypic $\left(\begin{array}{ll}\delta & 2 \mathrm{p}\end{array}\right)$ and genotypic $\left(\begin{array}{ll}\delta & 2 \mathrm{~g}\end{array}\right)$ standard deviations of the grand mean of the trait. Hence,

Genotypic cofficient of varation $(G C V)=\frac{\sqrt{\sigma^{2} g}}{X} X 100$ phenotypic cofficient of varation $(P C V)=\frac{\sqrt{\sigma^{2} p}}{X} X 100$

Where $x=$ population mean.

\section{Estimate of heritability}

Heritability (H2): Heritability in the broad sense for all characters was computed as per the formula adopted from (Allard, 1960).

$$
H^{2}=\frac{\sigma^{2} g}{\sigma^{2} p} X 100
$$

Where: $\delta 2 p=$ phenotypic variance, $\delta 2 g$ =genotypic variance, $\mathrm{H} 2=$ broad sense heritability.

\section{Estimation of expected genetic advance}

Expected genetic advance under selection assuming a selection intensity of $5 \%$ was computed following the formula developed by (Allard 1960).

$\mathrm{GA}=(\mathrm{K})(\delta \mathrm{p})(\mathrm{H} 2)$, where $\mathrm{GA}=$ expected genetic advance, $\mathrm{K}=$ selection differential that varies depending upon the selection intensity and stands at 2.056 for selecting $5 \%$ of the genotypes, $\delta \mathrm{p}=$ phenotypic standard deviation and $\mathrm{H} 2=$ heritability (in the broad sense)

Genetic advance as percent of mean was obtained as;

$$
G A(\% \text { of mean })=\frac{G A}{\bar{x}} \times 100 \%
$$

where $G A=$ Expected genetic advance mean percentage, $\quad \overline{\mathbf{x}}=$ population mean for the trait considered. 


\section{Correlation coefficients}

The correlations between yield and related traits as well as disease parameters traits were estimated using the method described by (Miller et al. 1958).

$$
\text { rpxy }=\frac{\operatorname{CoVpxy}}{\sqrt{\sigma^{2} p x \cdot \sigma^{2} p y}}
$$

Where: $\quad r p x y=$ phenotypic correlation coefficient between character $x$ and $y$, COVpxy $=$ phenotypic covariance between character $x$ and $y, \sigma^{2} p x=$ phenotypic variance for character $x$.

\section{RESULTS AND DISCUSSION}

\section{Analysis of variance (ANOVA) for} agronomic and disease parameters

S. tritici was first observed 57 days after planting (DAP) at Zadoks growth stage (GS) (five leaves on the main shoot) on infector rows. The disease appeared slightly on most of the test genotypes. Whereas, it was observed on few genotypes gradually at the late heading stage (GS 65 and 72). These results are in agreement with Said, (2016) who reported that $S$. tritici was first observed and recorded at Zadoks growth stage (GS) of Z15, 23 (five leaves on main shoot \& three tillers) from all treatments.

The analysis of variance was computed for disease parameters such as severity, area under disease development progress curve and septoria progress coefficient for 180 genotypes at the different phenological stages as presented in Tables 3 and 4. The results depicted that mean squares due to genotypes were significantly different for most $S$. tritici disease parameters such as area under diseases progress curve, disease severity and Septoria progress coefficient during the latter assessment periods or after the second assessment onwards for both all leaves (72 DAP) and flag leaf (88 DAP). This implied that there was significant variability among bread wheat genotypes in the response to $S$. tritici disease at both phenological stages and a clue to work further genetic analysis. This finding is in agreement with Abebe et al. (2015) and Mohammadi et al. (2012) those who reported a wide range of variability among wheat genotypes evaluated for S.tritici disease and other agronomic parameters. Gough (1978) also reported that a wide disease resistance variation occurred in different wheat genotypes for $S$. tritici and this variation is important for a breeding programme to develop high yielder and S.tritici resistant varieties. Developing septoria resistance varieties is one of the highest priorities in wheat breeding (Brown et al. 2015; Torriani et al. 2015).

The results of the analysis of variance for 180 bread wheat genotypes studied are presented in Table 5. The mean squares of the quantitative traits in the present study revealed that there is a highly significant difference $(\mathrm{P} \leq 0.01)$ among the tested genotypes (Table $5)$. This indicated the presence of adequate variability among the genotypes for all the traits studied. Similarly, several authors also reported the existence of an enormous amount of genetic variability for phenological and yield traits (Gerema et al. 2020; Kifle et al. 2016; Mesele et al. 2016). In the contrary to the present finding, Khan (2013) reported non -significant differences among bread wheat genotypes for grain yield, plant height and days to maturity. This disparity may be due to the environment-genotype interaction. The significant differences among studied bread wheat genotypes indicate the presence of genetic variability in the genotypes and it provides a good opportunity for selecting materials for wheat improvement programs.

\section{Estimation of phenotypic and genotypic parameters}

\section{Estimation of variability Components}

The estimated phenotypic coefficient of variation $(\mathrm{PCV})$ and genotypic coefficients of variation $(\mathrm{GCV})$ is presented in Table 6. The GCV value was ranged from $1.5 \%$ for days to maturity to $28.9 \%$ for grain yield, and PCV 
Table 3: Mean squares from analysis of variance for Septoria tritici disease parameters of 180 bread wheat genotypes evaluated for all leaves

\begin{tabular}{lllllll}
\hline Parameters & $\begin{array}{l}\text { Replica- } \\
\text { tion } \\
(\mathrm{Df}=1)\end{array}$ & $\begin{array}{l}\text { Geno- } \\
\text { types } \\
(\mathrm{Df}=179)\end{array}$ & Block & $\begin{array}{l}\text { Error } \\
(\mathrm{Df}=14 \\
9)\end{array}$ & Mean & CV \\
\hline Severity at 57 DAP (\%) & 0.04 & 0.185 & 0.17 & 0.09 & 1.35 & 19.05 \\
Severity at 65 DAP (\%) & 83.10 & 0.328 & 0.37 & 0.14 & 3.29 & 20.00 \\
Severity at 72 DAP (\%) & 0.96 & $0.616^{* *}$ & 0.44 & 0.32 & 8.00 & 21.50 \\
Severity at 80 DAP (\%) & 13.30 & $1.07^{* *}$ & 1.64 & 0.55 & 18.34 & 12.00 \\
Severity at 88 DAP (\%) & 0.73 & $1.69^{* *}$ & 0.88 & 0.54 & 31.53 & 15.40 \\
Severity at 96 DAP (\%) & 14.13 & $13.11^{* *}$ & 10.22 & 12.96 & 50.12 & 9.30 \\
Severity at 105 DAP (\%) & 0.15 & $1.55^{* *}$ & 1.45 & 0.97 & 63.32 & 23.00 \\
SPC & 0.20 & $0.578^{*}$ & 0.60 & 0.56 & 1.10 & 18.00 \\
AUDPC & 24374.40 & 56330.18 & 32360.87 & 30654.44 & 1001.90 & 9.30 \\
& & $* *$ & & & & \\
\hline N.T:
\end{tabular}

N.T: $\mathrm{Df}=$ degree of freedom, $\mathrm{CV}=$ Coefficient of variation, AUDPC $=$ Area under disease development curve, $\mathrm{DAP}=$ Days after planting, $\mathrm{SPC}=$ Septoria progress coefficient, ${ }^{*}$ and ${ }^{*}$ Significant difference at $\mathrm{p}<0.05, \mathrm{P}<0.01$, respectively.

Table 4: Mean squares from analysis of variance for Septoria tritici disease parameters of 180 bread wheat genotypes evaluated on flag leaves

\begin{tabular}{lllllll}
\hline Parameters & $\begin{array}{l}\text { Repilica- } \\
\text { tion } \\
(\mathrm{Df}=1)\end{array}$ & $\begin{array}{l}\text { Geno- } \\
\text { types } \\
(\mathrm{Df}=179)\end{array}$ & Block & $\begin{array}{l}\text { Error } \\
(\mathrm{Df}=14 \\
9)\end{array}$ & Mean & CV \\
\hline Severity at 80 DAP (\%) & 13.30 & 1.63 & 1.07 & 0.55 & 18.34 & 13.30 \\
Severity at 88 DAP (\%) & 63.95 & $60.24^{*}$ & 112.37 & 61.11 & 25.98 & 17.33 \\
Severity at 96 DAP (\%) & 14.13 & $10.22^{* *}$ & 13.11 & 12.96 & 49.06 & 18.10 \\
Severity 105 DAP (\%) & 256.72 & $151.14^{* *}$ & 110.58 & 69.79 & 63.09 & 14.31 \\
AUDPC & 19374.40 & $36330.18^{* *}$ & 32360.8 & 30654.44 & 1001.90 & 9.30 \\
\hline
\end{tabular}

$\mathrm{NB}: \mathrm{Df}=$ degree of freedom, $\mathrm{CV}=$ Coefficient of variation, $\mathrm{AUDPC}=$ Area under disease development curve, $\mathrm{AP}=\mathrm{Days}$ after planting, $\mathrm{SPC}=$ Septoria progress coefficient.

from $1.6 \%$ for days to maturity to $34.5 \%$ for grain yield. The GCV and PCV values were categorized as low $(<10 \%)$, moderate (10 to $20 \%)$ and high $(>20 \%)$ as indicated by (Deshmukh et al., 1986). Therefore, high PCV

and GCV were recorded for grain yield. Similar findings were reported by Geleta et al. (2020); Kifle et al. (2016); Mesele et al. (2016). Relatively moderate PCV and GCV values were recorded for $S$. tritici disease parameters such as SPC and \% severity, indicating that there is variability among the genotypes studied and there is a possibility to select for $S$. tritici disease resistant.

\section{Estimation of heritability and expected genetic advance}

According to Singh (2001), the heritability of a character is very high if $80 \%$ or more, moderate if ranged from $40-80 \%$, and low if less than $40 \%$. In the present study, heritability was ranged from moderate (49.1\%) for AUDPC to very high (88) for 
Table 5: Mean square from analysis of variance for 4 quantitative traits of 180 bread wheat genotypes

\begin{tabular}{lllllll}
\hline Parameters & Rep & Block & Msg & $\begin{array}{l}\text { Erorr(A. } \\
\text { lattice) }\end{array}$ & $\begin{array}{l}\text { Error } \\
\text { ( RCBD) }\end{array}$ & $\begin{array}{l}\text { CV } \\
\text { (A. lattice) }\end{array}$ \\
\hline $\begin{array}{l}\text { Days to } \\
\text { maturity }\end{array}$ & 9.4 & 0.4 & $4.8^{* *}$ & 0.7 & 0.6 & 0.6 \\
$\begin{array}{l}\text { Plant height } \\
\text { Grain yield }\end{array}$ & 28.8 & 44.3 & $83.5^{* *}$ & 31.9 & 33.9 & 6.6 \\
\hline
\end{tabular}

$\mathrm{N} \mathrm{B}: \mathrm{Msg}=$ mean of square for genotypes, A.lattice=alpha lattice

Table 6: Estimation of variance parameters, heritability and genetic advance for quantitative and Septoria tritici disease parameters of 180 bread wheat genotypes

\begin{tabular}{|c|c|c|c|c|c|c|c|}
\hline Parameters & $\sigma 2 \mathrm{~g}$ & $\sigma 2 p$ & GCV & $\mathbf{P C V}$ & Her & GA & GA(\%) \\
\hline $\begin{array}{l}\text { Percentage of disease se- } \\
\text { verity }\end{array}$ & 44.0 & 68.2 & 13.9 & 17.3 & 64.5 & 11.0 & 23.0 \\
\hline $\begin{array}{l}\text { Septoria Progress Coeffi- } \\
\text { cient }\end{array}$ & 1.4 & 2.2 & 36.1 & 46.2 & 61.1 & 1.9 & 58.1 \\
\hline $\begin{array}{l}\text { Total Area under de- } \\
\text { velopment progress } \\
\text { curve }\end{array}$ & 54.0 & 110.0 & 7.2 & 10.3 & 49.1 & 10.6 & 10.4 \\
\hline Days to maturity & 4.6 & 5.2 & 1.5 & 1.6 & 87.3 & 34.7 & 22.6 \\
\hline Plant height $(\mathrm{cm})$ & 67.6 & 99.5 & 9.6 & 11.7 & 88.0 & 1130.3 & 13.2 \\
\hline Grain yield $(\mathrm{kg} / \mathrm{ha})$ & 1401560 & 1998604 & 28.9 & 34.5 & 80.1 & 156869 & 38.3 \\
\hline
\end{tabular}

NB: $g 2 p=$ Genotypic variance, $\mathrm{GCV}=$ Genotypic coefficient of variation, $\mathrm{H}=$ Broad sense heritability, GA= genetic advance, $\mathrm{GA}(\%)=$ Genetic advance as percent of mean, $\mathrm{PCV}=$ phenotypic coefficient of variance, $\delta 2 \mathrm{p}=\mathrm{Phenotypic}$ variance.

plant height (Table 6). High heritability was estimated for days to maturity, plant height and grain yield (Table 6). Gerema et al. (2020) also reported that high heritability was recorded for grain yield. High heritability values for these traits indicated that the variation observed was mainly under genetic control and was less influenced by the environment. Moderate heritability was computed for disease parameters such as disease severity and septoria progress coefficient, which indicates the resistance genes to STB less influenced by the environment.

Heritability estimates along with genetic advances are normally more helpful in predicting the gain under selection than heritability estimates alone (Johnson et al. 1955). High heritability coupled with high genetic advance as percent of mean was observed for days to maturity and grain yield (Table 6). Moderate heritability coupled with high genetic advance as percent of mean was estimated for the percentage of disease severity and Septoria progress coefficient (Table 6). This indicated that these traits are controlled by additive genes and improvement through selection could be effective for days to maturity, grain yield, and resistance to $S$. tritici. Therefore, these traits should be taken into account while selecting superior and desirable plants for further improvement of grain yield and resistance to $S$. tritici disease. 
High heritability associated with moderate genetic advance was exhibited for plant height. This could be because of the predominance of non-additive gene action in the expression of this character.

\section{Correlation Coefficient Analysis}

Correlation between grain yield and disease parameters

Association among disease resistance traits and some of the agronomic and phenological traits presented in table 7 . Wheat yield was correlated with different disease parameters and those disease parameters were correlated with each other. The correlation coefficient analysis result revealed that percent coverage of disease, Septoria progress coefficient, and Percent disease severity had a negative association with the grain yield (Table 7). It implied that there is an inverse relationship between yield and disease parameters. The present finding is in agreement with Kidane et al. (2017) who reported grain yield conversely showed low correlations with all disease traits. Similarly, these disease parameters had non-significant and negative associated with plant height, 1000-kernels weight, grain filling period and days to heading (Table 7). This result shows that those genotypes with the short plant height (dwarf) and early grainfilled are less suffer with $S$. tritici disease infection. Similar results were reported by Danon et al. (1982). Abera et al. (2015) reported that plant height and thousand seed weight negatively correlated with severity. The number of seeds per spike and the grain size (reported as thousand-grain weight) is inversely correlated with SDS (Kidane et al. 2017). Days to maturity and heading had a negative and moderate association with disease parameters including SPC, PDC, and $\%$ severity. Genotypes having a shorter heading and maturity time have less infection, it could be contributed by disease escape mechanisms, i.e., early heading varieties escaping the disease spread and appearing more resistant as a consequence. The biological yield was negatively and moderately correlated with the severity of the disease and pycnidia but positively correlated with the Septoria progress coefficient (Table 7).

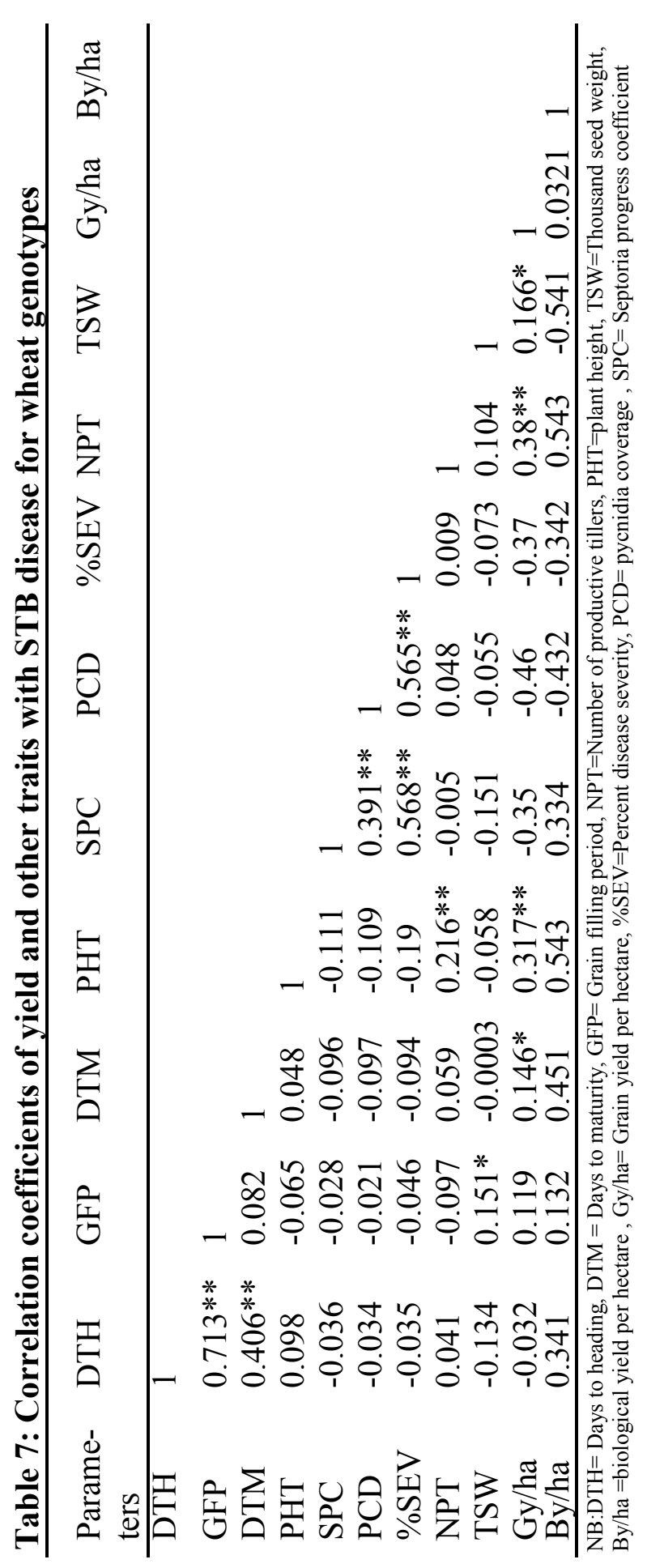




\section{CONCLUSION}

The present study showed that the existence of considerable variability among the tested wheat genotypes for $S$. tritici resistance, yield and other parameters. Therefore, these traits should be taken into account while selecting superior and desirable plants for further improvement of yield and $S$. tritici resistance in the development of high yielding and resistant genotype in bread wheat.

\section{REFERENCES}

Abera T, Alemu L, Getaneh W, Endale, H and Bekele K. 2015 Status of wheat Septoria leaf blotch in southwest and western Shewa zones of Oromiya regional state, Ethiopia. Research in Plant Sciences. 3:43-48.

Abebe T, Muez M. and Legesse M 2015 Field Response of Wheat Genotypes to Septoria tritici Blotch in Tigray, Ethiopia.Journal of Natural Sciences Research. 5:1.

Allard RW 1960 Principles of Plant Breeding. John Wiley and Sons, New York,500p.

Ayele B, Eshetu B, Betelehem B, Bekele H, Melaku D, Asnakech T, Melkamu A, Amare A, Kiros $\mathrm{M}$ and Fekede A 2008 Review of two decades of research on diseases of small cereal crops. In: Abrham Tadesse (eds.) Increasing crop production through improved plant protection Vol. I. Proceedings of 14th annual conference of plant protection society of Ethiopia 19-22 Dec. 2006 Addis Ababa., Ethiopia. 375-416.

Brown JKM, Chartrain L, Lasserre-Zuber P and Saintenac C 2015 Genetics of resistance to Zymoseptoria tritici and applications to wheat breeding. Fungal Genetics Biology. 79: 33-41.

Bako Agricultural Research Center (BARC) 2019 Annual Research progress report (unpublished docs).
Campbell CL and Madden LV 1990 Introduction to plant disease epidemiology. John Wiley and Sons, New York. USA.

Cools H J and Fraaije B A 2013 Update on mechanisms of azole resistance in Mycosphaerella graminicola and implications for future control. Pest Management . Science. 69: 150-155. doi: $10.1002 /$ ps.3348.

Cowger C, Hoffer ME and Mundt CC 2000 Specific adaptation by Mycosphaerella graminicola to a resistant wheat cultivar. Plant Pathology. 49:445-51.

Danon T, Sacks JM and Eyal Z 1982 The relationships among plant stature, maturity class and susceptibility to Septoria leaf blotch of wheat. Phytopathology. 72: 1037-1042.

Deshmukh SN, Basu MS and Reddy PS 1986 Genetic variability, character association and path Coefficients of quantitative traits in Virginia bunch varieties of groundnut. Indian Journal of Agricultural Science. 56: 515-518.

Dean R, Van Kan JAL, Pretorius ZA, Hammond-Kosack KE, Di Pietro A and Spanu PD 2012 The top 10 fungal pathogens in molecular plant pathology. Molecular Plant Pathology. 13: 414-430.

Duveiller E, Singh RP, and Nicol JM 2007 The challenges of maintaining wheat productivity: pests, diseases, and potential epidemics. Euphytica 157: 417-430. doi: 10.1007/s10681-0079380-z.

Eyal Z and O Ziv 1974 The relationship between epidemics of Septoria leaf blotch and yield losses in spring wheat. Phytopathology. 64:1385-1389.

Eyal Z, Scharen AL , Prescott JM and Van Ginke M 1987 The Septoria diseases of wheat: Concepts and methods of disease management. CIMMYT. Mexico, DF 
Eyal Z 1999 The Septoriatritici and Stagonosporanodorum blotch diseases of wheat. Eur. Journal of Plant Pathology. 105: 629-641.

FAO 2017 FAOSTAT Rome, available at: http://faostat.fao.org (accessed 16 January 2020).

Fones H and Gurr S 2015 The impact of Septoria tritici blotch disease on wheat: An EU perspective. Fungal Genetics and Biology. 79: 3-7. doi: 10.1016/j.fgb.2015.04.004.

Gerema $G$, Lule D, Lemessa F and Mekonnen T 2020 Morphological characterization and genetic analysis in bread wheat germplasm: A combined study of heritability, genetic variance, genetic divergence and association of characters. Agricultural Science \& 12(4): 1313-8820.

Technology,

Gladders P, Paveley ND, Barrie IA, Hardwick NV, Hims MJ and Langton S 2001 Agronomic and meteorological factors $\mathrm{a} \square$ ecting the severity of leaf blotch caused by Mycosphaerella graminicola in commercial wheat crops in England. Annual Applied Biology. 138: 301-311.

Gough FG 1978 Effect of wheat host cultivars on pycnidiospore production by Septoria tritici. Phytopathology .68:1343-1345.

Hailu E and Woldeab G 2015 Survey of Rust and Septoria Leaf Blotch Diseases of Wheat in Central Ethiopia and Virulence Diversity of Stem Rust Pucciniagraminis f. sp. Tritici. Advance Crop Science. 5: 3-2.

Hailu G, Tanner DG and Mengistu H 1991 Bread wheat Breeding and Genetics Research in Ethiopia: A Historical Perspective, Addis Ababa, IAR/ CIMMYT.

Johnson HW, Robinson HF and Cornstock RE 1955 Estimates of genetic and environmental Variability in
Soybeans. Agronomy Journal. 47: 314 $-318$.

Kidane YG, Hailemariam BN, Mengistu DK, Fadda C, Pè ME and Dell'Acqua M 2017 Genome-Wide Association Study of Septoria tritici Blotch Resistance in Ethiopian Durum Wheat Landraces. Frontiers in Plant Science. 8:1586.

Kifle Z, Firew M and Tadesse D 2016 Estimation of association among growth and yield-related traits in bread wheat (Triticum aestivum L.) genotype at Gurage Zone, Ethiopia. International Journal of Microbiology and Biotechnology. 1: 1-9.

Khan SA 2013 Genetic Variability and Heritability Estimates in F2 wheat Genotypes. International Journal of Agriculture and Crop Sciences. 5: 983 $-986$.

Kosina P, Reynolds M, Dixon J, and Joshi A 2007 Stakeholder perception of wheat production constraints, capacity building needs, and research partnerships in developing countries. Euphytica .157: 475-483.

Leroux P, Albertini C, Gautier A, Gredt M and Walker AS 2007 Mutations in the CYP51 gene correlated with changes in sensitivity to sterol 14 alphademethylation inhibitors in field isolates of Mycosphaerella graminicola. Pest Management Science. 63: 688-698.

Miller PA, Williams JC, Robinson HF, and Comstock RE 1958 Estimates genotypic implications in selection. Agronomic Journal. 50:126-131.

Mengistu H, Getaneh W, Yesh A, Rbka D and Ayele B 1991 Wheat pathology Research in Ethiopia. In: Hailu G, Tanner, DG, Mengistu H (eds). Wheat research in Ethiopia: A historical perspective. Addis Ababa. IAR/ CIMMYT, 173217. 
Mesele A, Wassu M and Tadesse D 2016 Estimation of heritability and genetic advance of yield and yield related traits in bread wheat (Triticum aestivum L.) genotypes at Ofla District, Northern Ethiopia. International Journal Plant Breeding. 10: 31-37.

Mohammadi M, Ramezanpour S, Navabpour S, Soltanloo H, Kalateharabi M, Kia S 2012 Genetic analysis and heritabilities of resistance to Mycosphaerella graminicola in wheat. Crop Breeding Journal. 1:35-42.

Pietravalle S, Shaw MW, Parker SR, and van den Bosch F 2003 Modeling of relationships between weather and Septoria tritici epidemics on winter wheat: a critical approach. Phytopathology. 93: 1329-1339.

Ponomarenko A, Goodwin SB, Kema GHJ 2011 Septoria tritici blotch (STB) of wheat. Plant Health Instructor. doi:10.1094/PHI-I-20110407-01.

Rezenne F 1993 A review of weed science research activities on wheat and barleyin Ethiopia. pp. 121-148. In: Tsedeke Abate (ed.). A Review of Crop Protection Research in Ethiopia. Addis Ababa, Ethiopia:IAR

Saari EE and Prescott JM 1975 A scale for appraising the foliar intensity of wheat diseases. Plant Disease. 59: 377-380.

Said A and Hussein T 2016 Epidemics of Septoria Tritici Blotch and its
Development over Time on Bread Wheat in Haddiya-Kambata Area of Southern Ethiopia. Journal of Biology, Agriculture and Healthcare. 6(1): 4757.

SAS 2009Version 9.3.Inc. Carry, North California, USA.

Sharma RC and Duveiller E 2007 Advancement toward new Spot Blotch resistant wheat in south Asia.Crop Science. 47: 961-968.

Singh DN 2001 Heritability and genetic advances in linseed (L. usiataissimum L.).Journal of Research Birsa Agricultural Reserach. 13: 73-74

Tar'an B, Zhang C, Warkenting T, Tullu A and Vandenberg A 2005 Genetic diversity among varieties and wild species Accessions of pea ( Pisum sativum L) based on molecular markers, and morphological and physiological characters. Genome. 48: 257-272.

Torriani SFF, Melichar JPE, Mills C, Pain N, Sierotzki $\mathrm{H}$ and Courbot M 2015 Zymoseptoria tritici: a major threat to wheat production, integrated approaches to control. Fungal Genetic Biology. 79: 8-12.

Tadesse W, Bishaw Z and Assefa S 2019 Wheat production and breeding in Sub -Saharan Africa: Challenges and opportunities in the face of climate change. International Journal of Climate Change Strategies and Management. 11 (5): 696-715. 